\title{
Rancang Bangun Flow Meter Trainer Kit di Politeknik Negeri Batam
}

\author{
Qoriatul Fitriyah" and Muhammad Prihadi Eko Wahyudi \\ *Politeknik Negeri Batam, Batam, Indonesia \\ Electrical Engineering Study Program \\ Jl.Ahmad Yani, Batam Centre, Batam 29461, Indonesia \\ E-mail: fitriyah@polibatam.ac.id.ac.id
}

\begin{abstract}
Abstrak
Flow Meter Trainer Kit dirancang karena keterbatasan peralatan laboratorium terkait di Politeknik Negeri Batam. Flow Meter Trainer Kit merupakan alat ukur untuk aliran fluida yang dilengkapi dengan penambahan tekanan dalam bentuk alat peraga. Secara umum, proses aliran air dimulai dengan mengisi penuh tangki air lalu pompa akan bekerja untuk mengalirkan air melalui pipa, melewati pressure meter dan rotameter yang bertugas untuk membaca hasil pengukuran debit aliran fluida sekaligus mengatur jumlah aliran fluida. Selanjutnya, air akan mengalir melewati water flow sensor dan kembali lagi ke dalam tangki. Modul praktikum akan dikembangkan berdasarkan trainer kit ini berdasarkan metode Kerucut Pengalaman oleh Kosasih.
\end{abstract}

Kata kunci: Flow meter trainer kit, flow meter, rotameter, pressure meter, aliran fluida, debit aliran fluida

\begin{abstract}
Flow Meter Trainer Kit is designed because of the limited associated laboratory equipment at Politeknik Negeri Batam. Flow Meter Trainer Kit is a measuring tool for fluid flow which is equipped with the addition of pressure in the form of visual aids. In general, the process of water flow begins with a full filling of water tanks and then the pump will work to flow the water through pipes, passing pressure meters and rotameters whose duty is to read the results of fluid flow discharge measurements while adjusting the amount of fluid flow. Furthermore, water will flow through the water flow sensor and back into the tank. The practicum module will be developed based on this trainer kit according to Cone Experience method by Kosasih.
\end{abstract}

Keywords: Flow meter trainer kit, Flow meter, rotameter, pressure meter, fluid flow, fluid flow discharge

\section{Pendahuluan}

Politeknik Negeri Batam merupakan satu-satunya perguruan tinggi negeri di Pulau Batam yang terdiri dari 4 (empat) jurusan dan 15 (lima belas) program studi dalam strata D3 maupun D4 dengan total mahasiswa aktif sebesar 4560 mahasiswa [1]. Dari jumlah tersebut, sekitar 1500 mahasiswa tergabung dalam jurusan Elektro yang menaungi 5 program studi yaitu Teknik Elektronika, Teknik Mekatronika, Instrumentasi, Manufaktur Mikroelektronika dan Robotika.
Salah satu tantangan yang dihadapi oleh laboratorium elektronika di berbagai institusi pendidikan di Indonesia adalah keterbatasan alat ukur karena umumnya pengadaan barang secara impor dari luar negeri sehingga harga cenderung mahal. Salah satu solusinya adalah dengan membuat perangkat praktikum sendiri [2]. Salah satu perangkat praktikum yang popular adalah trainer kit. Trainer kit merupakan media instruksional yang dapat digunakan untuk menyalurkan pesan dari pengirim ke penerima, sehingga dapat merangsang pikiran, perasaan, perhatian dan minat siswa sehingga proses belajar terjadi. Menurut kesimpulan Aditya 
Prabhandita, dengan adanya trainer kit, persentase peningkatan kompetensi praktikum naik sebesar 50\% [3].

Fokus penelitian ini adalah pada pembuatan Flow meter trainer kit jurusan Teknik Elektro di Politeknik Negeri Batam khususnya prodi Teknik Instrumentasi, dilengkapi dengan pengembangan modul praktikum terkait. Pengukuran dilakukan dengan melakukan pengambilan data aliran fluida beserta penambahan tekanan. Secara umum proses aliran air dimulai dengan mengisi penuh tangki air lalu pompa air akan bekerja untuk menarik air ke atas melalui pipa dan masuk ke dalam alat ukur rotameter. Kemudian air tersebut akan mengalir kembali ke dalam tangki. Rotameter merupakan alat ukur yang digunakan untuk menampilkan hasil pengukuran dalam bentuk analog.

\section{Tinjauan Pustaka}

\subsection{Media Pembelajaran}

Menurut Kosasih (2007:10), media pembelajaran cenderung diartikan sebagai alat-alat grafis, fotografis atau elektronis untuk menangkap, menyusun, memproses, dan menyusun kembali informasi visual atau verbal. Media juga dapat diartikan sebagai segala sesuatu yang dapat dipergunakan untuk menyalurkan pesan, merangsang pikiran, perasaan, perhatian, dan kemauan siswa, sehingga dapat terdorong terlibat dalam proses pembelajaran [4].

Adapun tahapan belajar bisa diilustrasikan dengan kerucut pengalaman sebagai berikut:

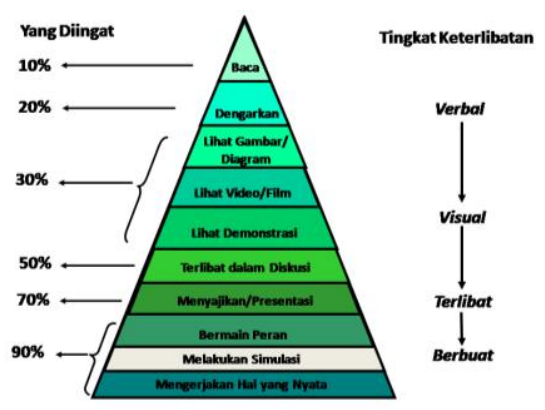

Gambar 2. 1 Kerucut pengalaman [5]
Semakin ke atas, semakin kecil kegiatan tersebut berimplikasi pada mahasiswa, yang berarti bahwa semakin sedikit pengetahuan yang diingat dan diserap [6]. Dari kerucut tersebut juga bisa diketahui bahwa dengan melakukan simulasi atau percobaan, tingkat keterserapan materi bisa mencapai $90 \%$.

Adapun manfaat media pembelajaran menurut Darmanto (2017:10) antara lain adalah:

1. Penyampaian materi perkuliahan dapat diseragamkan.

2. Proses belajar mengajar menjadi lebih menyenangkan.

3. Proses belajar lebih interaktif

4. Jumlah waktu belajar mengajar menjadi lebih efisien.

5. Kualitas belajar dapat lebih ditingkatkan.

6. Proses belajar dapat dilakukan tidak hanya di kelas.

7. Sikap positif siswa terhadap bahan belajar maupun proses belajar dapat ditingkatkan

8. Peran guru berubah ke arah yang lebih positif dan produktif

\subsection{Rotameter}

Rotameter merupakan salah satu instrumen tertua dalam pengukuran aliran.

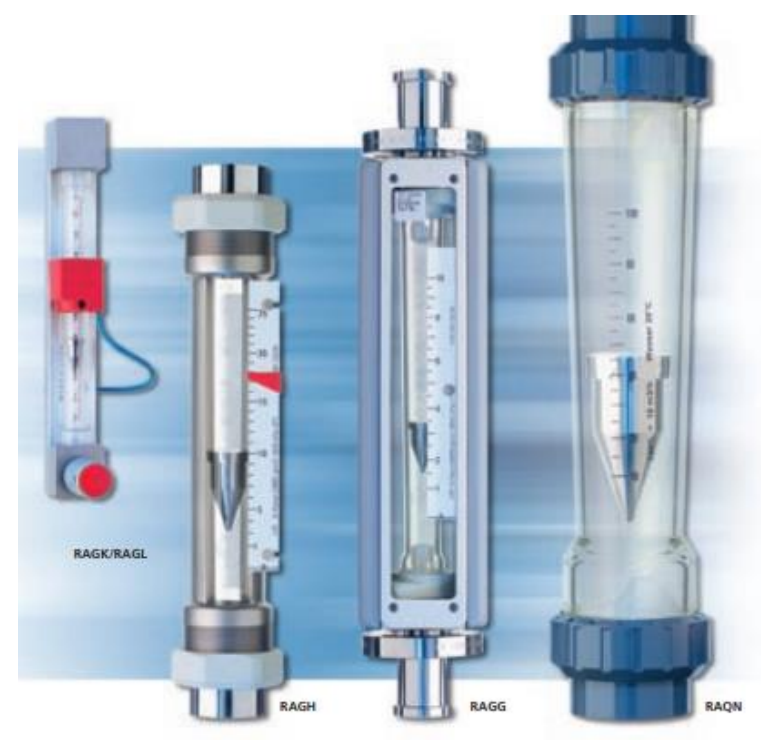

Gambar 2. 2 Rotameter [7] 
Terdapat pengapung di dalam rotameter yang berbentuk kerucut. Pengapung ini akan naik ketika aliran fluida naik berdasarkan prinsip mekanik sederhana. Rotameter dibuat umumnya dalam pipa vertikal. Ketika fluida mengalir melalui pipa, gaya gravitasi menyeimbangkan diri dengan gaya aliran resistif sehingga posisi dari pengapung akan menunjukan nilai dari aliran medium yang digunakan[7] .

\subsection{Pressure Meter}

Pressure meter merupakan instrumen mekanik yang didesain untuk mengukur tekanan internal dan/atau vakum dari sebuah sistem [8].

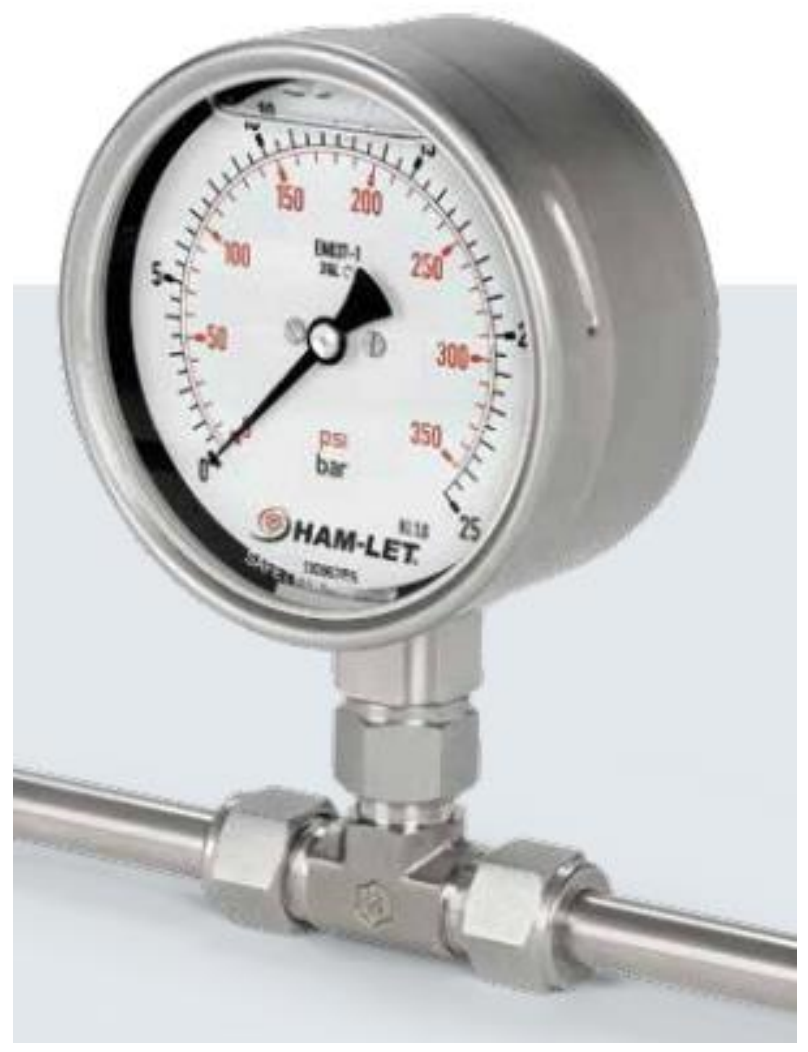

Gambar 2. 3 Pressure meter [9]

Pressure meter mekanik memanfaatkan tabung dalam yang dihubungkan dengan rantai dan batang yang bekerja bersama-sama untuk menggerakkan penunjuk. Ketika tekanan di dalam tabung naik, tabung akan sedikit terbuka. Saat tabung terbuka, gerakan memicu sistem rantai dan batang yang menggerakkan penunjuk pada pressure meter. Jumlah dari pergerakan terbuka ini terjadi secara relatif dengan tekanan di dalam tabung. Gerakan ini yang kemudian menunjukkan gerakan jarum yang berupa angka tekanan [10].

\subsection{Penelitian-penelitian menggunakan Flow Meter Trainer Kit}

Penelitian menggunakan flow meter trainer kit telah banyak dipasarkan dalam dunia industri. Salah satu website resmi yang menjual produk ini adalah www.gunt.de dengan produk bernama HM 500 Flowmeter trainer. Trainer kit ini dilengkapi dengan berbagai tipe alat ukur untuk mendukung prinsip kerja flowmeter tersebut. Berbagai alat ukur yang terdapat pada HM 500 ini tergantung pada medium dan pengaplikasian sesuai dengan kebutuhan. Namun, perkiraan harga HM 500 Flowmeter trainer kurang lebih sekitar RP 100.000.000,- [11]

\section{Metode Penelitian}

\subsection{Perancangan Blok Diagram}

Perancangan sistem ini dibuat untuk mengetahui proses pengukuran tentang aliran fluida dengan penambahan tekanan. Proses awal pengukuran ini mempersiapkan segala peralatan yang akan digunakan, termasuk proses pengisian tangki air hingga penuh. Air kemudian akan dikeluarkan dari tangki dengan bantuan pompa air. Selanjutnya, pompa akan meneruskan air tersebut ke dalam rotameter. Rotameter akan membaca debit aliran fluida dengan satuan liter/menit. Pembacaan mengenai debit aliran fluida diatur menggunakan kran, sehingga dapat menampilkan hasil pengukuran sesuai dengan besar atau kecilnya pemutaran pada kran. Selanjutnya, air akan mengalir kembali ke dalam tangki. Blok diagram dapat dilihat sebagaimana ditunjukkan pada gambar berikut ini: 


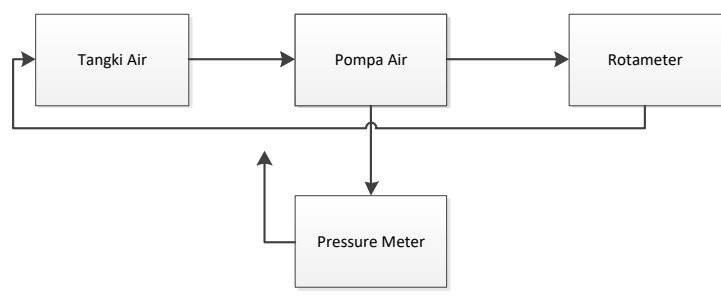

Gambar 3.1 Blok Diagram Trainer Kit

\subsection{Perancangan Desain Mekanik}

Perancangan desain mekanik flow meter trainer kit menggunakan software Autodesk AutoCAD. Alat ini dibuat dengan penyangga atau dudukan yang berfungsi untuk meletakkan pompa air dan tangki air. Ukuran penyangga tersebut juga disesuaikan dengan fungsi kegunaannya. Trainer kit dibuat dengan vertikal untuk memudahkan aliran air pada pipa.

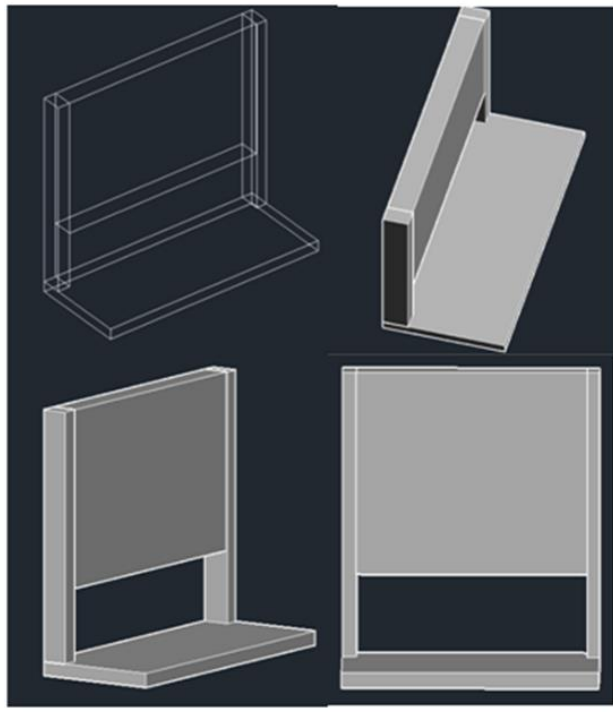

Gambar 3.2 Desain Mekanik Trainer kit

\section{Hasil dan Pembahasan}

Setelah perencanaan blok diagram dan desain mekanik dilakukan, langkah selanjutnya adalah melakukan instalasi alat, ujicoba pengukuran dan pembuatan modul praktikum.

\subsection{Instalasi Alat}

Pekerjaan dilakukan terlebih dahulu dengan pembuatan papan penyangga yang kemudian dilanjutkan dengan instalasi peralatan.

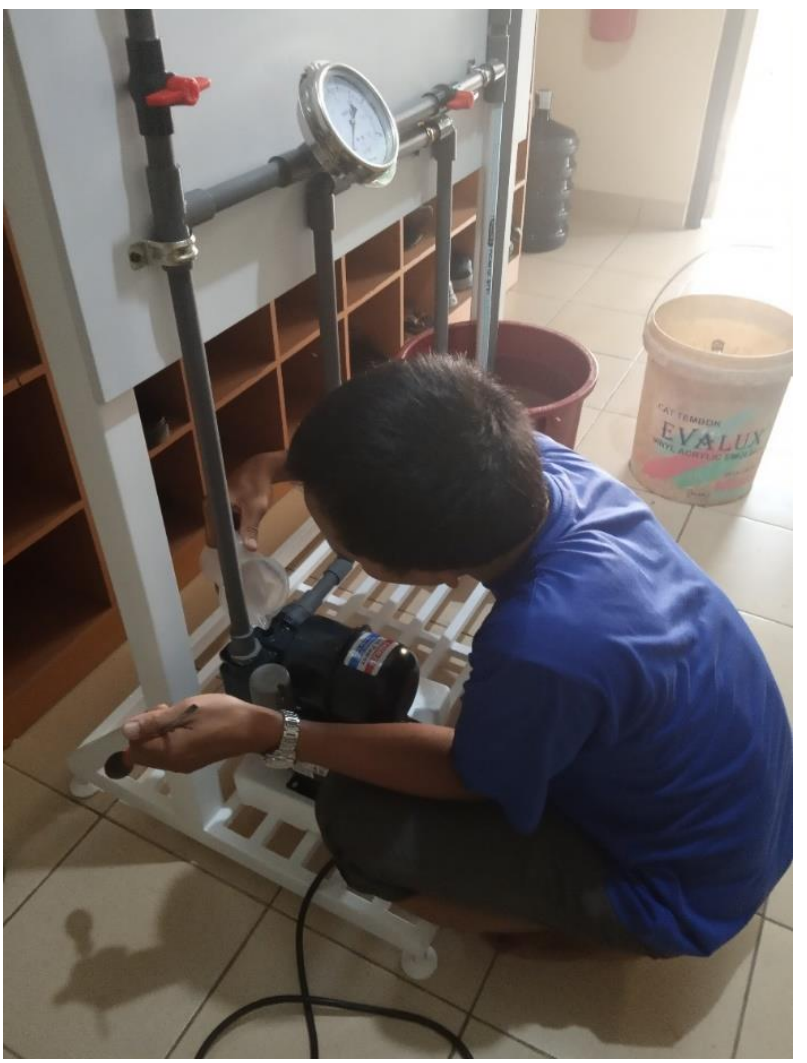

Gambar 4.1 Pembuatan Papan Penyangga dan Instalasi Peralatan

\subsection{Uji Coba Pengukuran}

Berdasarkan hasil uji pengukuran yang dapat dilihat di Tabel 1 menunjukkan bahwa nilai tekanan $\left(\mathrm{kg} / \mathrm{cm}^{3}\right)$ tidak tergantung pada nilai debit aliran fluida (lpm). Hal ini menunjukkan bahwa tekanan merupakan variabel yang independen dan bisa berdiri sendiri dari aliran fluida. 


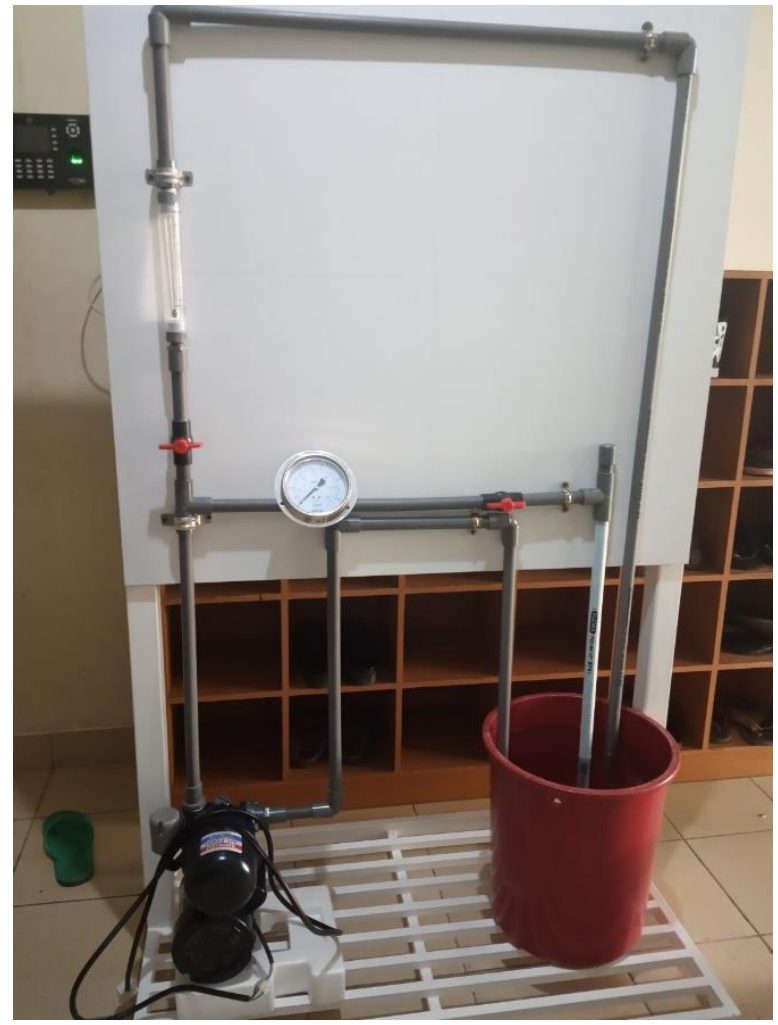

Gambar 4.2 Uji Coba Pengukuran Fluida

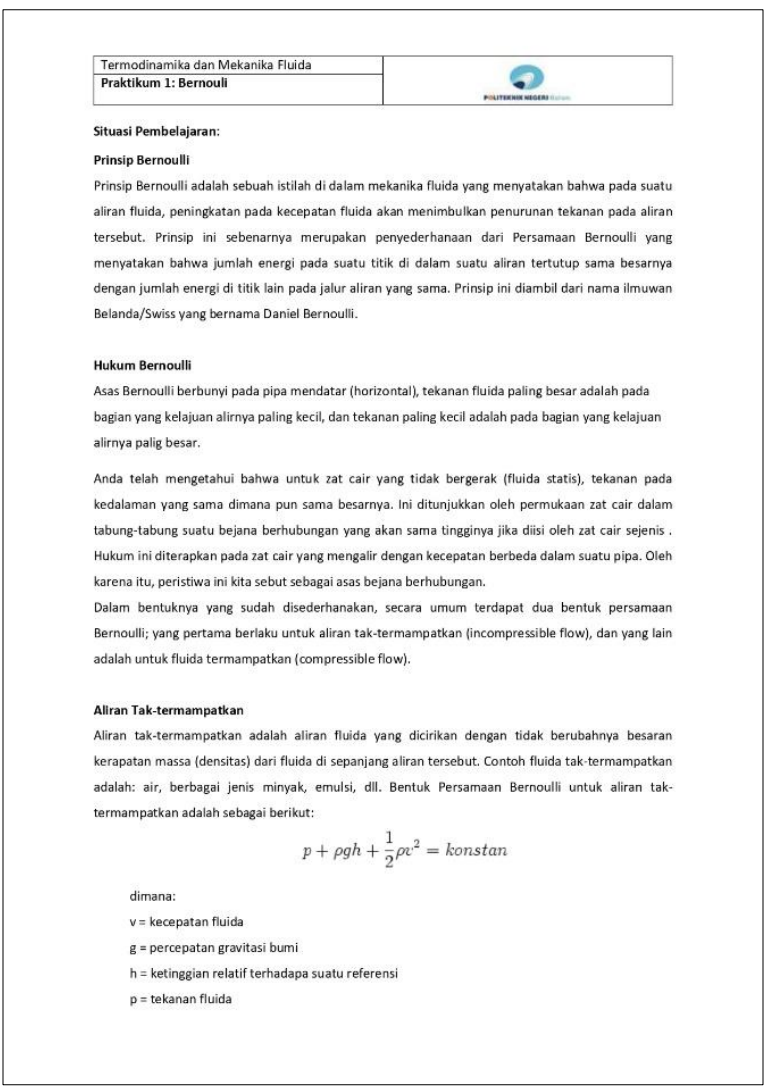

Gambar 4.3 Contoh Modul Praktikum

\section{Ucapan Terima Kasih}

Terima kasih kepada P2M Politeknik Negeri Batam selaku sponsor utama penelitian ini.

\section{Referensi}

[1] Batam, P.N. Sejarah Politeknik Negeri Batam. 2017; Available from: https://www.polibatam.ac.id/sejarah/.

[2] SYIFAUL FUADA, A.W.W., Desain dan Implementasi Virtual Laboratory Materi Osilator Analog berbasis IC OP-AMP. Jurnal ELKOMIKA, Juli - Desember 2016. 4: p. Halaman 134 - 147.

[3] Prabhandita, A., PENGEMBANGAN DAN IMPLEMENTASI MEDIA PEMBELAJARAN TRAINER KIT SENSOR ULTRASONIK PADA MATA DIKLAT PRAKTIK SENSOR DAN TRANSDUSER DI SMK N 2 DEPOK SLEMAN, in Teknik Mekatronika. 2012, UNY: Yogyakarta.

[4] Kosasih, R.A.d.A., Optimalisasi Media Pembelajaran. 2007: Gramedia Widiasarana.

[5] Dale, E., Audio-Visual Methods in Teaching. 1969, New York: Rinehart \& Winston.

[6] M.Pd., D.D. Media Pembelajaran. 2017.

[7] Yokogawa, Variable Area Flowmeter Rotameter The Original, R.Y.G.C. KG., Editor. 2004.

[8] Trerice, Pressure Gauges DESIGN \& OPERATION, Trerice, Editor. 2017.

[9] HAM-LET, Industrial Mechanical Pressure Gauges, HAM-LET, Editor. 2014.

[10] Engineering, B., Pressure Gauge Working Principle, B. Engineering, Editor. 2014.

[11] Hanburg, G., HM 500 Flowmeter Trainer, Hanburg, Editor. 2018. 